Adi Staempfli, Lesley Adshead \& Joan Fletcher (2015)

\title{
Ready for qualified practice? A comparative study of capability for critical reflection and analysis of MA Social Work and MA Step Up to Social Work students at the end of second placement.
}

\author{
Social Work Education 13 October 2015 (Online)
}

\section{Abstract}

Social Work education is faced with substantial changes. New programmes like Step Up to Social Work have emerged and were evaluated in relation to intake, programme development and subjective student experiences. The lack of evidence on outcomes of such programmes was addressed in this study. In a comparative study of a MA in Social Work and a MA in Step Up to Social Work, the authors analysed students' capability to critically reflect on and analyse social work practice scenarios at the end of their final placement at one university. The PCF domain 'Critical Reflection and Analysis' was operationalised and the study design employed qualitative and quantitative data analysis. Demographic data, academic marks achieved during social work education and written reflections on case vignettes from the two programmes were analysed statistically. The findings suggest that, while there are some differences in outcomes between the programmes, they are not statistically significant. However, reflections on children and family vignettes were significantly better $(\mathrm{U}=185, p=0.008)$. Thematic analysis revealed considerable variation in the levels of curiosity and critical thinking and that respondents who framed their answers with reference to policy guidance, theory and research often extended their critical thinking.

Keywords: social work; education; professional training; research; comparative studies; reflection; capability 


\section{Introduction}

Loss of public confidence in the light of high profile child deaths has seen a major drive to improve standards in social work, including social work education. Concerns have been raised about the calibre of practitioners entering the profession and about the quality of judgement and decision-making.

Consequently the MA Step Up To Social Work (SU), specialising in children and families social work over an 18-month period, was developed. After the first two cohorts this is now offered as a postgraduate Diploma in Social Work, as are the more recent 'Frontline' and 'Think Ahead' programmes for children and families' and adult mental health respectively.

There is disagreement about whether social work education should offer generalist or specialist pathways (Trevithick, 2011). Narey (2014, p.39) concluded that 'universities should be encouraged to develop [specialist] degrees for those intending to work in children's social work'; while Croisdale-Appleby (2014) suggested that generalist programmes should be supplemented by specialist qualifying degrees, but not replaced. Trevithick (2011, p. 151) suggested that social work training and education should focus on 'enabling students to perfect their generalist knowledge and skills in key areas' and on enhancing the capability of students to integrate theory and practice 'in ways that "speak" to the situations regularly encountered in social work' (Trevithick, 2011, p. 146). The central question is whether the development of specialised expertise commences during qualifying education or thereafter. Narey (Community Care, 2015) said "I think we've got a choice, we either give social workers more time to learn the job, extend the degree to a four-year degree, or make sure we use that time, which is desperately limited, for the things that really count". 
Social workers' use of knowledge and research to inform practice is seen as a concern (SWRB, 2011; Munro, 2011) and addressing this in social work education and research is a priority. Most evaluations focus on the views of students or tutors.

Outcomes in relation to knowledge and skills gained, their impact on professional and organisational practices and on the quality of service users and carers wellbeing remains under researched (Carpenter 2011).

SU programmes were evaluated at various points (DfE, 2013, 2014), with the effectiveness of improving the quality of those entering the profession and the processes of employer agencies and Higher Education Institutions (HEI) collaboration (DfE, 2013) and the feedback of trainees on the first and second cohorts (DfE 2014, p.16) being studied. Croisdale-Appleby $(2014$, p. 27) cited evidence from HEIs who criticised the SU programmes for being 'process and task driven, weak on reflective practice and on understanding anti-oppressive approaches, and not adequately teaching the ability to use theory to inform practice'.

There is little research, comparing these newer fast track routes into social work with traditional MA programmes. In reviewing the completion rates of students on the SU programmes the authors of the first report (DfE, 2013) compared a traditional MA programme with the SU programmes, using figures from two lead HEI's. The authors of the second report commented that it 'would have been helpful to have been able to survey a cohort of students on a 'traditional' master's course to explore any similarities and differences' (DfE 2014, p. 16).

In 2012 and 2013 the University was responsible for both a MA in Social Work (MA) and a SU programme and was able to undertake such comparative research. The authors would like to contribute to an evidence informed critical discussion of outcomes of social work education. Both social work programmes were evaluated through regular 
feedback and close collaboration between the stakeholders ensured that the quality of the programmes was monitored not only through the University's own quality assurance but also from external perspectives.

The SU was developed on the basis of the existing MA and was based on the same curriculum. The teaching and learning and assessment methods were the identical. Differences were that the MA offered two pathways in the second year (adult and children and families), while the SU focussed mainly on children and families social work, which was reflected in the content of modules and the practice learning setting in the second year. The SU ran for 18 months with no breaks, compared to 24 months of the MA. The teaching on the second part of the SU programme was delivered mainly by advanced level practitioners, rather than by lecturers. The group size of the two programmes differed with 31 students on the MA and 13 on the SU.

In light of the discussion around a perceived lack of capability to integrate theory, research, law and practice (SWRB, 2011; Munro, 2011) and of a weakness of SU programmes on reflective practice (Croisdale-Appleby, 2014), and in the context of the debate about specialist versus generalist approaches to social work education, the authors decided to design a study which would enable an analysis and comparison of the students' ability to reflect and analyse between the generalist MA and more specialised SU. The intention was to develop an understanding of the students' capability in terms of 'acquisition of knowledge and skills' (Carpenter, 2005). The research question was: What differences, if any, are there in social work students' capability to critically reflect and analyse between students on two different MA in Social Work programmes at the end of their final placement and how might these be explained? 
The ability of social workers to critically reflect on their work, including making reference to sources of knowledge that have informed their interventions is central to practice and to the development of professional judgement and expertise (SfC and DfE, undated). The Professional Capability Framework (PCF) is used for assessment of social workers in England and has a specific domain for critical reflection and analysis. In reality this capability permeates every domain of social work practice. Professional practice is marked by an integration of knowledge, skills and values (Staempfli, Kunz \& Tov, 2012). Thus, linking theory and practice is pivotal for social work practice, education and continuous professional development.

While reflective practice is seen as the key to link theory and practice (Moon, 2004), its concept remains ill defined (Wilson, 2013). Ruch (2007, p. 660) defines reflective practice as 'an approach that seeks to respond to ... challenges by acknowledging the uniqueness of each individual and practice encounter and the diverse types of knowledge required to address effectively the complex issues these encounters generate'. However, with few exceptions (Tov, Kunz \& Stämpfli, 2013; Fook \& Gardner, 2007) there is a lack of clear process models for reflection (Jennert, 2008). The literature suggests that reflection needs to include thinking about best evidence (Knott \& Scragg, 2007), practice (Gray \& Schubert 2010), emotions (Fook \& Gardner, 2007), learning strategies (Jennert, 2008) and always lead to action (Payne, 2009).

\section{Methodology}

As critical reflection and analysis are thought processes, the study design required students to make these explicit. Use of vignettes is seen as a suitable method to assess the capability to reflect (Carpenter, 2005) and this has been successfully used (MacIntyre, et al., 2011; MacIntyre \& Green Lister, 2010, Orme et al., 2009). MacIntyre 
et al. (2011, p. 210) concluded that this enables assessment of outcomes in relation to acquisition of knowledge and skills (see Carpenter, 2005).

Vignettes developed by MacIntyre \& Green Lister (2010) were used. These describe scenarios of a children and families and an adult social work situation and allow reflection on the assessment and decision-making, required to address the complexities of contemporary social work practice. The students were asked to answer a number of questions designed to elicit: knowledge brought to the analysis; application of that knowledge to scenario; assessment and analysis of the situation and interventions skills (MacIntyre \& Green Lister, 2010).

Using a mixed method approach (Robson, 2002) enabled quantitative comparison of the students' capability to reflect between the programmes and a qualitative analysis of the reflections. This approach provides richer and more nuanced understandings of educational outcomes in relation to knowledge and analyticalreflective capability (Carpenter, 2005).

Ethical approval was granted by the Research Ethics Committee of the University. Students were notified in advance that participation would be voluntary, that data collected would be anonymised before scoring and that analysis would be carried out by an independent researcher with no links to either programme.

\section{Data collection}

All students of the MA $(n=31)$ and SU $(n=13)$ were asked to participate after completion of their final statutory placement. The two vignettes were allocated randomly, but ensuring that from each programme approximately the same number of each vignette was completed by students on either pathway. Participants were provided with a computer, but no books, phones, Internet access, or other resources were available. They were asked to write a reflective critical discussion on the case vignette 
by answering the questions. The time allowed was 60 minutes. All written reflections were anonymised and any information in relation to programme type or pathway of the participant was removed.

In addition, data on age, gender, ethnicity and academic marks obtained on the programmes were obtained from the University's student records.

\section{Data analysis}

An independent researcher in collaboration with research staff from the University carried out the scoring and analysis. The researcher worked with the anonymised reflections. These were first scored and analysed using a quantitative approach, analysed qualitatively.

Quantitative data analysis.

In order to assess the quality of the students' reflections the authors developed theoretical variables based on the PCF domain of 'Critical Reflection and Analysis' at the level 'end of last placement' (TCSW, 2012). The participants were familiar with the concept of critical reflection and analysis and have practised this throughout their programme. The PCF describes this capability in the following way:

'Social workers are knowledgeable about and apply the principles of critical thinking and reasoned discernment. They identify, distinguish, evaluate and integrate multiple sources of knowledge and evidence. These include practice evidence, their own practice experience, service user and carer experience together with research-based, organisational, policy and legal knowledge. They use critical thinking augmented by creativity and curiosity.' (TCSW, 2012).

Based on this, six knowledge and two further domains were identified and dependent 
variables were developed. For each a question was developed to aid scoring:

1. Did the student identify legal and policy knowledge?

2. Did the student identify organisational and contextual knowledge?

3. Did the student identify theoretical and research-based knowledge?

4. Did the student identify service user, carer, and professional expertise?

5. Did the student identify knowledge of risk and resilience factors?

6. Did the student identify knowledge of interventions and associated skills?

7. Did the student make use of critical thinking? and

8. Are the decisions made in the discussion based on social work values and the application of professionalism?

Each variable was scored using a Likert type scale (MacIntyre et al., 2011). For variables one to six a scale of 'not identified' (score one), 'just identified' (two), 'identified' (three), 'strongly identified' (four) and 'emphasised' (five) was applied. Variable seven was scored from 'not used' (one) to 'emphasised' (five) and variable eight from 'not based' (one) to 'emphasised' (five).

As all reflections were analysed by one researcher, inter-rater reliability (MacIntyre et al., 2011) was not an issue. A moderation process was applied to develop the variables and to address subjectivity. The three researchers independently analysed randomly chosen reflections. Scores were compared and points of divergence, discussed. This showed that some variables overlapped, and others were insufficient to encompass all knowledge. Further modifications were made and the revised variables and associated questions presented above were used for scoring.

For each variable 'descriptors' of knowledge, skills and values were developed to enhance consistent scoring across cases. These descriptors were based on the range of 
responses given and on what the researchers expected to see, reflecting their professional expertise and knowledge of the content of the programmes. The transcripts were all re-read and re-scored; each section of text, which matched a descriptor was colour coded, making comparisons easier and scoring more consistent. A final moderation of the highest and lowest scored responses revealed consensus on scoring with little divergence of opinion.

Following the rating of each vignette, the data was collated and imported to SPSS (Version 22). For each participant a Likert scale composite score was calculated (Boone \& Boone, 2012). Further data on students (age, ethnicity and marks for all assessment components) was added and a composite score for the marks achieved on the programme was calculated. These variables allowed statistical analysis of the two groups, using cross tabulation (Fisher's exact test) or rank sum tests for non-parametric testing of two independent small samples (Mann Whitney U and Kruskal-Wallis Test) (Nachar, 2008; Robson, 2002).

Qualitative analysis.

To gain a more in depth understanding of the reflections these were read several times during the scoring process and were compared with each other. Differences and similarities across cases became clearer and early ideas of patterns and descriptive codes were developed.

This analysis was not undertaken with any pre-determined questions or categories. It was essentially an inductive process, in which the themes emerged from the reading of the transcripts and were 'grounded' in that data (Glaser and Strauss, 1967). At a subsequent phase the initial codes were explored in more detail, noting the links and they were organised into broader over-arching themes. 


\section{Findings}

\section{Participants}

Of the 44 enrolled students, 31 participated $(\mathrm{N}=31)$, which represents a response rate of 68\%. Participants did not differ significantly from those who did not participate. Of the 31 participants, 17 completed a vignette with an adult's and 14 with a children and families' scenario. Twenty-three participants completed the children and families' pathway, either on the MA or the SU and eight completed an adults' pathway on the MA. Fourteen students reflected on a vignette corresponding with their pathway, while 17 completed a vignette which differed from this. This led to the following six subgroups (independent variables):

\begin{tabular}{|r|c|c|c|c|}
\hline Type of programme & \multicolumn{2}{|c|}{ MA } & SU & Total \\
\hline Pathway & Adult & C\&F & C\&F & \\
\hline Adults' Vignette & 4 & 8 & 5 & 17 \\
\hline Children \& Families' Vignette & 4 & 5 & 5 & 14 \\
\hline Total & 8 & 13 & 10 & 31 \\
\hline
\end{tabular}

Table 1 Number of participants by programme, pathway and allocated vignette.

\section{Quantitative analysis of reflections on vignettes}

On first examination of the eight variables the authors observed that variables two, four and six appeared to be normally distributed across both programmes. Variables one, three, five, seven and eight were skewed to the left, indicating lower scores. MA students in particular were less able to include theoretical and research-based knowledge and values in their reflections and were less likely to use critical thinking. Making use of legal and policy knowledge seemed to be a weakness on both programme types, as was the inclusion of risk and resilience factors. 
The scores of these eight Likert scale variables were used to calculate the composite score of all eight variables ('overall score') as a measure for capability to reflect and analyse. The MA participants had an overall score of 2.89 (Range 1.63 to 4.00, SD 0.59), the SU of 3.19 (Range 2.13 to 4.25 , SD 0.75). These are equivalent to the middle scores of 'identified' 'used' 'based'. The overall scores were used for further statistical analysis.

The Independent-Samples Mann-Whitney U Test showed no significant differences in the overall score $(\mathrm{U}=130, p=0.306)$ between the programmes. The authors concluded that participants from the two programmes did not differ significantly in relation to their capability to reflect on and analyse the vignettes.

Further, the overall score across the six different subgroups (see table 1) based on programme type (MA or SU), pathway (C or A) and vignette type (C or A) were statistically analysed. ${ }^{1}$ A Kruskal-Wallis test showed that there was a statistically significant difference in the overall score between the different subgroups $(\mathrm{H}=11.975, p$ $=0.035)$ with an overall score of 3.70 for SUCC, 3.28 for MAAC, 3.16 for MAAA, 3.03 for MACC, 2.68 for SUCA and 2.47 for MACA. Comparing the subgroups with the same pathway and vignette type revealed no significant difference between MACC and SUCC (U=21.5, $p=0.059)$ and between MACA and SUCA $(\mathrm{U}=25.0, p=0.462)$. Thus, there is no clear recognisable pattern with the highest score for the SU students

1 The subgroups analysed were MA students on the adults' pathway who reflected on an adult Vignette (MAAA) and on a children and families' vignette (MAAC), MA students on the children and families' pathway who reflected on an adults' vignette (MACA) and on a children and families' vignette (MACC), SU students (children and families' pathway) who reflected on an adults' vignette (SUCA) and on a children and families' vignette (SUCC). 
who reflected on a vignette from their own pathway and the second highest score from MA students reflecting on a vignette divergent from their pathway.

There was no statistically significant difference in overall scores by pathway. However, there was a significant difference in overall scores by vignette type $(\mathrm{U}=185$, $p=0.008)$. This is explained by the much better outcomes for the reflections on the children and families vignettes.

Not surprisingly, the reflections by students who reflected on a vignette in their chosen pathway, were significantly better than those where pathway and vignette type differed $(\mathrm{U}=58.5, p=0.016)$, providing evidence for validity of the scoring. It further revealed that SU students who specialised in children and families' social work for most of their programme and reflected on such a vignette had much better outcomes compared to the MA students who analysed a vignette from their own pathway. This could not be explained by the composite score for their programme assessment results $(\mathrm{U}=79.0, p=0.11)$, thus indicating that there was no bias due to allocation of vignette types to academically stronger students.

To gain a better understanding of the quality of the reflections the findings from the thematic analysis of the written reflections is presented.

\section{Qualitative analysis of reflections on vignettes}

From the qualitative analysis three over-arching themes emerged: oversimplification; relationship with other professionals (and use of supervision) and variable use of legal and policy knowledge.

\section{Oversimplification.}

There was considerable variation in the levels of curiosity and critical thinking demonstrated by students - the least curious and critical often oversimplified the case, 
evident in three key ways: placing too much reliance on presenting information alone, not fully recognising the context and the inter-relatedness of people's lives and not recognising the multifaceted nature of such concepts such as 'empowerment' and 'having a voice'.

Over reliance on referral/presenting details. Some of the respondents accepted assertions in the scenario at face value, while others weighed things up, took a measured approach, and stated that it would be easy to make assumptions. These students were clear that presenting details and professional views were open to question:

'...my first assumption was that John was grooming and/or sexually abusing Elizabeth and most probably had or is abusing Claire. I feel these assumptions can hinder decision making and cause you to make impulsive decisions ... (28 SUCC number of respondent, programme type, pathway, and vignette).

Not fully recognising the context and the inter-relatedness of people's lives. Some responses suggested that if the broader family and social context and the interrelatedness of lives are not taken sufficiently into account, then an overly simplified interpretation of, and response to, the circumstances can follow.

'David has not been actively encouraged to seek his own housing and this may the reason why he has not shown any desire to move out. I think it would be important to highlight to the family the difference between independence and dependence.' (21 MACA)

More developed responses showed that the social worker stood back and balanced up the competing voices, recognising the inter-relatedness of individual needs and perspectives and also referred to the skills needed to help reconcile any differences.

'...it would be important not to allow the situation to be led by people's anxieties or fears for David. It could well be that there [are] competing agendas that it may be necessary to consider and unpack. This could involve skills around conflict resolution, an understanding of family dynamics and how people with learning 
disabilities can be oppressed by not putting their wishes at the centre. It could mean a multi-disciplinary approach involving not only his parents, but possibly an older adults' team to support them, David's support worker and social worker, but also an advocate for him.' (5 MAAA)

Not recognising the multifaceted nature of such concepts as 'empowerment' and 'having a voice'. Most saw empowerment as an important goal but left it at that - many did not give a clear indication of process - how this might be achieved. The best responses indicated the importance of rapport and relationship building, and using appropriate tools, for promoting purposeful communication, which could lead to an empowering intervention and were able to describe the process of empowerment within the intervention,

'I would want to discuss with David specific options about what living elsewhere would be like, to make sure he understood it. I would talk about actual properties ... the level of support available ..., who else lived there, how often he would see his parents ... I would use pictures, memory aids and other assistive tools where necessary.' (13 MAAA)

Whilst all respondents recognised David's lack of voice their response varied. A minority saw this as a fight they saw that David needed support to 'be heard' and perhaps needed an ally but were in danger of turning others in David's network, family members or other professionals into adversaries. Others took a much more nuanced stance and took into consideration the wider context: '...changing David's current lifestyle, in even the most minor ways, could have significant impact on not only his life but also his parent's lives' (8 MACA).

\section{Relationship with other professionals (and use of supervision)}

There were key differences in the way participants related to and used the expertise of 
other professionals. The respondents who scored highest drew on a range of professional expertise in order to develop a strategy,

'I would speak with my manager and convene a strategy discussion.... I would also want to get information from the other professional's working with the children...I would want to speak to their schools ...I would seek the advice of the Health Visitor... [and] the family's GP.' (11 MACC)

Others acknowledged the expertise of relevant professionals but highlighted referral to those professionals rather than a more consultative or collaborative approach. They passed the case on.

Taking an unrushed approach required an ability to 'hold a case' whilst different perspectives are explored and the level of complexity ascertained, and this perhaps demands more confidence and authority in relation to the social work role, balanced by a clear understanding of duties in relation to risk. People's approach to supervision and support from managers differed. The highest scoring respondents used this support to provide a space for reflection, whilst they continued holding the case,

'Discussions with line managers, whether within formal or informal supervision is crucial. No decisions should be made by social workers alone. Case discussions enable social workers to think through the issues, analyse the situation from the information gained, and to be supported to make decisions regarding appropriate interventions and next steps.' (24 SUCC)

Variable use of legal and policy knowledge

Differences between the students who responded to the adults' and those who responded to the children and families' vignette showed that the latter mostly attempted to frame responses with reference to law and policy, often both.

'Likely an initial and core assessment would be initiated and, dependent upon the information gleaned, the local authority would have to take a decision on the next 
steps. Options include Police Protection, an Emergency Protection Order, an Initial Child Protection Conference (most likely given information detailed), allocating as Child In Need or No Further Action. Any EPO or similar measures would need to be proceeded by a strategy discussion and possibly a legal planning meeting, if necessary.' (16 SUCC)

Clarity on the law and policy, lent a sense of authority. In contrast, others seemed tentative, did not seem guided by law or policy and perhaps doubted their own authority: 'If this was a real scenario, I would speak with my manager and possibly take this to an initial assessment.' (9 SUCC). Those students who responded to the children and families' vignette without clear reference to the legal framework took a scattergun approach, with lots of referrals, rather than a strategic approach, utilising the expertise of all the appropriate agencies in a coordinated way.

In relation to the adults' vignette there was far less direct reference to the law, or statutory responsibilities and where laws were mentioned they were seldom referenced directly in relation to guiding the social work process. Failure to refer to the law did not so much affect people's responses regarding the adult with learning disabilities, but many overlook the rights related to his parents as carers.

Participants who framed their answers with reference to policy guidance or to theory and research often extended their critical thinking,

'The LSCB 2010 also tells us that when mothers are consumed and overwhelmed by what is happening to them in domestic abuse situations, they are likely to be unable to meet the meet the needs of their child...the children may also be suffering from neglect ....' (4 SUCC)

\section{Discussion}

The authors have operationalised the PCF domain 'Critical Reflection and Analysis' to develop eight variables. These were used to create a Likert scale composite 
score (Boone and Boone, 2012). The better outcomes for reflections on vignettes in the students' own pathway point to a validity to these variables.

The PCF description of 'critical reflection and analysis' refers to evidence (Knott \& Scragg, 2007), practice (Gray \& Schubert 2010) and learning strategies (Jennert, 2008) as suggested in the literature on reflection. However, the consideration of emotion (Fook \& Gardner, 2007) is not expressed in this PCF domain and purposeful planning for action (Payne, 2009) is only implied with reference to decision-making. A review of the descriptor in the light of this is suggested.

There are clear limitations of this study. First, it is limited by its scope, scale and focus on just one university. However, the recruitment for the SU programme used a different admissions process, aiming to attract 'high calibre' postgraduate students. Second, as both programmes are based on very similar curricula, the results may be an expression of this similarity, rather than an indication as to the general comparability of the students' capability for reflection and analysis across the programmes. Third, while the domain of critical reflection and analysis is pivotal for social work capability, this study has specifically only addressed this domain. The findings may have been different, if the other domains had been studied. Clearly, no generalised conclusions in relation to SU and MA social work programmes can be made and the authors would welcome a replication of this study with a greater sample from a range of universities.

The authors were concerned that condensing the programme to 18 months with no breaks could have an impact, as reflection requires time (Moon, 2004). Statistical analysis however, showed no significant difference between the MA and SU students' capability to critically reflect on and analyse the vignettes. We found that MA (mean overall score 2.89) and SU (3.19) achieved both middle scores ('identified', 'used' or 
'based'). This somewhat dispels worries raised by HEI's in Croisdale-Appleby's review (2014) that SU programmes are weak on reflective practice.

However, there were apparent - although not statistically significant differences in relation to the inclusion of law and policy, theory and research, service user, carer and professional expertise, knowledge of interventions and organisational contexts and risk and resilience factors, as well as in the application of critical thinking and values in the written reflections of the participants. This confirms previous discussions in the literature (SWRB, 2011; Munro, 2011). The qualitative analysis further showed that students demonstrated considerable variation in the levels of curiosity and critical thinking and those scoring lowest often oversimplified the case by placing too much reliance on presenting information alone and by not fully recognising the complexity and inter-relatedness of people's lives and consequent interventions.

While quantitative analysis revealed that students from both programmes did not score highly on legal and policy knowledge, participants reflecting on the children and families' vignette generally made a clear attempt to frame the response with reference to law or policy. Respondents who framed their answers with reference to policy guidance or to theory and research often extended their critical thinking. Thus, there is real value in enabling students to relate theory and practice.

In the qualitative analysis the theme of relationship with other professionals showed that some students tended to develop a collaborative approach while others did not mention wider consultation or collaboration and were inclined to refer the case on. The ability to 'hold a case' whilst different perspectives were explored and the level of complexity was ascertained, demands a more developed level of confidence and authority in relation to the social work role, as well as a clear understanding of duties in relation to risk. Baginsky (2013) argues that social workers need to stay in post for a 
sustained period to develop "transferable and contextualised knowledge that expert professionals grounded in specific contexts can bring to the whole" (p. 6). With reference to Fook et al. (2000, cited in Baginsky, 2013) she contends that experts are able to interact in reflexive and responsive ways by recognising multiple perspectives in complex situations. Therefore, in order for the emergent social workers in our study to develop into experts, they will need to gain experience while continuing to engage in reflective practice, developing their knowledge and practice.

Both qualitative and quantitative analyses showed considerable differences between the students who responded to the adults' vignette and the children and families' vignette with significantly higher scores for the latter. Students who reflected on a situation from their own pathway specialism produced significantly better outcomes. This finding supports the idea that there is scope for specialised programmes such as SU as Narey (2014) suggested. However, as overall the SU and MA students did not differ significantly in their ability to critically reflect and analyse, the authors conclude that an exclusive approach is not necessary, supporting Croisdale-Appleby's (2014) view that generalist programmes should be supplemented, rather than replaced.

In the light of these findings regarding the relative weakness of integrating theory and research into the reflections, the researchers would suggest that programmes at postgraduate level need to focus more on the integration of different forms of knowledge. This could be by fostering a better understanding of reflective practice models, which explicitly include all forms of knowledge, and their application in university and practice learning. Another important aspect is to enhance the research capability of social work students. This study was conducted after the students' formal research methods training but before they completed their own research dissertation. Powell and Orme (2011) argue that formal teaching of research methods is not 
sufficient for building research capacity. It is indeed important to build first-hand experience of conducting research. However, the shortening of subsequent SU programmes and other fast track routes to a postgraduate Diploma means that this engagement in empirical work is threatened. The authors hypothesise that the capability to critically reflect and analyse will be affected and that students, who do not engage in primary research in their professional socialisation, will not be able to develop their ability to link and critique different forms knowledge and research with practice.

The SU programme had a different financial basis compared with the MA. Croisdale-Appleby (2014, p. 26) found that 'fast track entry schemes were seen to benefit from being particularly well-funded (...). Students receive support in the form of substantial bursaries in the case of SU, or salaries in the case of Frontline.' The question that arises then is, whether such funding is justified if the outcomes are not significantly different, as our study would suggest.

\section{Conclusion}

The main research question, was, what are the differences between the MA and SU students' capability to critically reflect and analyse and how these might be explained? The authors found no significant difference in the quality of the reflections between the students of the two programmes. However, there was a significant difference in the quality in the reflections between children and families' and adults' vignettes, and for reflections on vignettes, which corresponded with the pathway of the student. Oversimplification; relationship with other professionals and use of supervision, and variable use of legal and policy knowledge emerged as strong themes in the qualitative analysis. This research suggests that the SU students are not necessarily the 'high calibre' practitioners, they are considered to be, nor are they much different in their ability to critically reflect and analyse. The authors hope that this study 
will inform discussions and further research into the different programme types in social work education. Further studies making use of similar methodologies might be used to investigate the differences between these types of programmes, possibly across all domains of the PCF. The researchers invite a deliberation of the validity of the variables developed. This might lead to further development of variables for the other PCF domains. The research hopes to add to examination of the generalist versus specialist debate, as well as a further consideration of ways to improve the integration of theory, practice and values. 


\section{References}

Baginsky (2013) Retaining experienced social workers in children's services: the challenge facing local authorities in England. Retrieved from https://www.kcl.ac.uk/sspp/policyinstitute/scwru/pubs/2013/reports/baginsky13retaining.pdf

Boone, H. N. and Boone, D. A. (2012). Analyzing Likert Data. Journal of Extension, 50(2), 1 - 5. Retrieved from http://www.joe.org/joe/2012april/pdf/JOE_v50_2tt2.pdf

Carpenter, J. (2005). Evaluating Outcomes in Social Work Education. London: Social Care Institute for Excellence. Retrieved from http://www.scie.org.uk/publications/misc/evalreport.pdf

Carpenter, J. (2011). Evaluating Social Work Education: A Review of Outcomes, Measures, Research Designs and Practicalities. Social Work Education: The International Journal, 30(02), 122-140. doi: 10.1080/02615479.2011.540375

Community Care (2015) It is time to split adults' and children's social work education, says Martin Narey. Retrieved from http://www.communitycare.co.uk/2015/07/10/time-split-adults-childrens-socialwork-education-says-martin-narey/

Croisdale-Appleby, D. (2014). Re-visioning social work education. An independent review. Retrieved from https://www.gov.uk/government/uploads/system/uploads/attachment_data/file/28578 8/DCA_Accessible.pdf

Department for Education (DfE) (2013) Step up to Social Work Programme Evaluation 2012: The Regional Partnerships and Employers Perspectives. Research Report. Retrieved from https://www.gov.uk/government/publications/step-up-to-social-workprogramme-evaluation-2012-the-regional-partnerships-and-employers-perspectives 
Department for Education (DfE) (2014) The Views of Step Up to Social Work Trainees Cohort 1 and Cohort 2. Research Report. Retrieved from https://www.gov.uk/government/publications/the-views-of-step-up-to-social-worktrainees-cohorts-1-and-2

Fook, J. \& Gardner, F. (2007). Practising critical reflection. A resource handbook. Maidenhead: McGraw Hill Open University Press.

Glaser, B. G. \& Strauss, A. L. (1967). The Discovery of Grounded Theory: Strategies for Qualitative Research. Chicago: Aldine Publishing Company.

Gray, M. \& Schubert, L. (2010). Turning Base Metal into Gold: Transmuting Art, Practice, Research and Experience into Knowledge. British Journal of Social Work 40, 2308-2325. doi: 10.1093/bjsw/bcq047

Jennert, T. (2008). Ganzheitliche Reflexion auf dem Weg zu Selbstorganisiertem Lernen [Holistic reflection on the pathway to self regulated learning], bildungsforschung, 5(2), 1-18. Retrieved from http://bildungsforschung.org/index.php/bildungsforschung/article/view/76

Knott, C. \& Scragg, T. (Eds.) (2007). Reflective Practice in Social Work. Exeter: LearningMatters.

MacIntyre, G. \& Green Lister, P. (2010). Evaluating learning using vignettes. In H. Burgess \& J. Carpenter (Eds.), The outcomes of social work education: developing evaluation methods. (pp. 26 - 33). Southampton: The Higher Education Academy Subject Centre for Social Policy and Social Work. Retrieved from http://www.swap.ac.uk/docs/monograph2_oswe.pdf

MacIntyre, G.; Green Lister, P.; Orme, J.; Crisp, B. R.; Manthorpe, J.; Hussein, S.; Moriarty, J.; Stevens, M.; \& Sharpe E. (2011). Using Vignettes to Evaluate the Outcomes of Student Learning: Data from the Evaluation of the New Social Work 
Degree in England. Social Work Education: The International Journal, 30, 207-222. doi: 10.1080/02615479.2011.540397

Moon, J. (2004). A Handbook of Reflective and Experiential Learning: Theory and Practice. Oxon: Routledge.

Munro, E. (2011). The Munro Review of Child Protection: Final Report - A Child Centred System. London: Department of Education. Retrieved from https://www.gov.uk/government/uploads/system/uploads/attachment_data/file/17539 1/Munro-Review.pdf

Nachar, N. (2008). The Mann-Whitney U: A Test for Assessing Whether Two Independent Samples Come from the Same Distribution. Tutorials in Quantitative Methods for Psychology, 4, 13-20. Retrieved from http://www.tqmp.org/Content/vol04-1/p013/p013.pdf

Narey, M., Sir (2014) Making the education of social workers consistently effective. Report of Sir Martin Narey's independent review of the education of children's social workers. Retrieved from https://www.gov.uk/government/publications/making-the-education-of-socialworkers-consistently-effective

Orme, J.; MacIntyre, G.; Green Lister, P.; Cavanagh, K.; Crisp, B. R.; Hussein, S.; Manthorpe, J.; Moriarty, J.; Sharpe, E. \& Stevens, M. (2009). What (a) Difference a Degree Makes: The Evaluation of the New Social Work Degree in England. British Journal of Social Work, 39, 161-178. doi: 10.1093/bjsw/bcm095

Payne, M. (2009). Critical reflection and social work theories. In R. Adams; L. Dominelli \& M. Payne (2009). Critical Practice in Social Work. (pp. 91 - 104). New York: Palgrave Macmillan. 
Powell, J. and Orme, J. (2011). Increasing the Confidence and Competence of Social Work Researchers: What Works? British Journal of Social Work, 41, 1566-1585. doi: 10.1093/bjsw/bcr027

Robson, C. (2002). Real World Research. A Resource for Social Scientists and Practitioner-Researchers. Oxford: Blackwell.

Ruch, G. (2007) Reflective Practice in Contemporary Child-care Social Work: The Role of Containment. British Journal of Social Work, 37, 659-680. doi:10.1093/bjsw/bch277

Skills for Care (SfC) and Department for Education (DfE) (undated). Further information about holistic assessment against the professional capabilities framework (PCF). Retrieved from http://www.skillsforcare.org.uk/Document-library/Socialwork/Support-and-assessment/Further-information-to-supportholistic\%20assessment.pdf

Stämpfli, A.; Kunz, R. \& Tov, E. (2012). Creating a bridge between theory and practice: working with key situations. European Journal of Social Education, 22/23, 60-78. Retrieved from www.feset.org/fileadmin/content/English/Documents/Euro_Journal_2012.pdf

TCSW (2012). Professional Capabilities Framework. Retrieved from http://www.tcsw.org.uk/ProfessionalCapabilitiesFramework/

Tov, E.; Kunz, R. \& Stämpfli, A. (2013). Schlüsselsituationen der Sozialen Arbeit: Professionalität durch Wissen, Reflexion und Diskurs in Communities of Practice. [Key Situations in Social Work: Professionalism through knowledge, reflection and discourse in communities of practice.] Bern: hep.

Social Work Reform Board (SWRB) (2011). Implementing SWRB proposals to improve the provision of social work degree programmes. Final statement on social work education. London: SWRB. Retrieved from 
http://www.tcsw.org.uk/uploadedfiles/thecollege/media_centre/improving\%20the $\% 2$ 0quality $\% 20$ and $\% 20$ consistency $\% 20$ of $\% 20$ initial $\% 20$ qualifying\%20social\%20work $\% 20$ education\%20and\%20training\%20final.pdf

Trevithick, P. (2011). The generalist versus specialist debate in social work education in the UK. In J. Lishman (Ed.) Research Highlights: Volume on Social Work Education. ( pp 233-254). London: Jessica Kingsley.

Wilson, G. (2013). Evidencing Reflective Practice in Social Work Education: Theoretical Uncertainties and Practical Challenges, British Journal of Social Work, 43, 154-172. doi: 10.1093/bjsw/bcr170 